\title{
Adults with disabilities who reported excellent or good quality of life had established a balance of body, mind, and spirit
}

Albrecht GL, Devlieger PJ. The disability paradox: high quality of life against all odds. Soc Sci Med 1999 Apr;48:977-88.

QUESTION: How do adults with disabilities understand and describe their quality of life in relation to physical and social environments?

\section{Design}

Qualitative approach using semistructured interviews.

\section{Setting}

Chicago, Illinois, USA.

\section{Participants}

153 adults (median age 53 y, 51\% women, $45 \%$ African-American, $50 \%$ single and never married, $51 \%$ high school graduates, $62 \%$ living with others) with a disability (arthritis, spinal cord injury or paralysis, cerebral palsy, multiple sclerosis, orthopaedic conditions, head injury, HIV, AIDS, heart conditions, eye or vision problems, chronic obstructive pulmonary disease, diabetes mellitus, chronic pain, addiction, or mental illness). The sample was generated through contacts in community based disability groups, government benefit agencies, shelters for the homeless, and acute hospitals.

\section{Methods}

Adults were interviewed in English or Spanish for approximately 2.5 hours and responded to open ended questions about their disability, their perceived quality of life, and how the disability affected quality of life. The data were transcribed, translated, analysed, and reported with division into 2 groups: self reported excellent or good quality of life ( $55 \%$ of the cohort) and fair or poor quality of life ( $45 \%$ of the cohort).

\section{Main findings}

Participants who reported an excellent or good quality of life felt that this was attributable to feelings of control over their bodies, minds, and lives, including being able to drive; being able to perform expected roles; having a "can do" attitude; finding purpose, meaning, and harmony in life; having a spiritual foundation and outlook; constructing and living in a reciprocal social world, including emotional give and take; and feeling satisfied when comparing oneself with others. Adults with disabilities did not deny or diminish their disability but felt satisfaction came from doing a good job with their lives. They reported that they had developed a balance of body, mind, and spirit. Many spoke of their faith or rediscovered spirituality.

Participants with a poor or fair quality of life reported that this related to the experience and loneliness of having pain. They felt de-energised by constant fatigue and other aspects of the disability, loss of control of mental or body function, and having no clear purpose or spiritual outlook on life. A discrepancy between what one wanted to do and what one could do was often described.

\section{Conclusion}

Adults with disabilities who reported excellent or good quality of life had built and maintained a balance among body, mind, and spirit and were in harmony with their environment.

\section{COMMENTARY}

This well executed qualitative study by Albrecht and Devlieger makes an important contribution to our understanding of how disabled people exercise control over their lives. It shows that by maintaining a harmonious relation with body, mind, and spirit, individuals are able to cope with the consequences of their disability. The findings build on existing work that emphasises how those with a disability are able to live a meaningful and valued social existence. They are not passive victims to be pitied but are able to establish a good quality of life in the same way as those who do not have a disability.

None the less, despite the value of the study's approach, caution should be exercised. Overemphasising individual coping strategies creates a danger that "poor" adjustment to disability is seen as a personal failure. This viewpoint does not recognise how many of the difficulties faced by disabled people occur because of the inability of the wider society to accommodate difference. Studies examining people's experience of disability should also take account of the wider social context in which disability assumes meaning. Many of the difficulties faced by disabled people, for example, are a consequence of social disadvantage and discrimination. Individuals have to cope with this as much as the clinical consequences of their disability. ${ }^{1}$

The study provides nurses with an understanding of disability that enables them to offer support that builds on the existing coping strategies of individuals. This ensures care is appropriately informed by the views of disabled people rather than on what practitioners assume is best for the individual. To this extent, disabled people are not tragic victims at the mercy of their impairment but active agents exercising control over their lives.

Karl Atkin, DPhil Principal Research Fellow Centre for Research in Primary Care University of Leeds Leeds, UK

Dr G L Albrecht, School of Public Health, University of Illinois, 2035 West Taylor Street, Chicago, IL 60612, USA Fax +13129965356. 